J. Math. and Its Appl.

E-ISSN: 2579-8936

P-ISSN: $1829-605 \mathrm{X}$

Vol. 14, No. 2, Desember 2017, 157-167

\title{
Pemodelan Biaya Garansi Dua Dimensi (Studi Kasus: PT. Indomobil Prima Niaga Sidoarjo)
}

\author{
Valeriana Lukitosari $^{1}$, Adhella Dwi Nur Saidah ${ }^{2}$ dan Titik Mudjiati ${ }^{3}$ \\ 1,2,3 Departemen Matematika, Fakultas Matematika Komputasi dan Science Data, \\ Institut Teknologi Sepuluh Nopember (ITS), Surabaya 60111, Indonesia \\ valerianaluki@gmail.com
}

\begin{abstract}
Abstrak
Penentuan biaya garansi sangat penting bagi perusahaan. Berapa biaya garansi yang tepat akan ditambahkan pada harga penjualan suatu produk. Biaya garansi yang terlampau kecil dapat merugikan perusahaan/produsen. Sebaliknya biaya garansi terlalu tinggi dapat merugikan konsumen. Pemberian garansi dapat meningkatkan rasa aman konsumen terhadap mutu produk. Garansi merupakan kesepakatan kontraktual antara produsen dan konsumen, dimana produsen bersedia melakukan perbaikan atau penggantian terhadap produk yang mengalami kerusakan selama periode garansi yang telah ditentukan. Dengan demikian, untuk menentukan biaya garansi diperlukan keterkaitan antara kerusakan dengan biaya perbaikan/penggantian. Pendekatan kerusakan dalam model dilakukan dengan melihat umur dan pemakaian produk, dimana kerusakan diasumsikan berdistribusi Weibull. Penelitian ini menghasilkan formulasi ekspetasi biaya garansi dua dimensi. Selain itu diperoleh hubungan besarnya ekspetasi biaya garansi produk sebanding dengan peningkatan umur dan pemakaian dari produk.
\end{abstract}

Kata kunci: Biaya Garansi; Distribusi Weibull; Umur; Kerusakan

\section{Pendahuluan}

Manajemen garansi merupakan tantangan yang harus dihadapi banyak produsen/perusahaan saat ini. Garansi adalah jaminan yang dikeluarkan oleh perusahaan terhadap pelanggan saat membeli produk. Hal ini dimaksudkan untuk melindungi 
pelanggan dari kerusakan manufaktur atau bahan pada produk. Perusahaan menyediakan unit pengganti atau pengembalian uang kepada pelanggan. Jaminan biasanya terbatas, mencakup beberapa jenis cacat selama jangka waktu tertentu, sehingga item yang dijual dalam garansi tidak meluas tanpa batas selama masa produk. Apabila terdapat klaim yang tidak sesuai, garansi melindungi produsen dari klaim konsumen yang menyebabkan produsen mengalami kerugian. Sehingga garansi bermanfaat bagi produsen dan konsumen.. Dilihat dari sisi lain, garansi merupakan penawaran yang menarik dalam penjualan produk. Sehingga pemberian garansi menjadi salah satu strategi promosi yang dapat ditempuh perusahaan untuk meningkatkan penjualan, Menezes dan Quelch (1990).

Pada awalnya kebijakan garansi dikelompokkan kedalam dua kebijakan. Namun saat ini, kebijakan garansi berkembang menjadi bervariasi sesuai kebutuhan dan jenis produk. Terdapat tiga kebijakan utama yaitu kebijakan garansi satu dimensi, garansi dua dimensi dan garansi tambahan. Kebijakan garansi satu dimensi dikarakteristikkan oleh satu atribut, misalnya umur produk atau pemakaian. Kebijakan garansi dua dimensi dikarakteristikan oleh dua atribut, dimana satu dimensi merepresentasikan waktu dan dimensi yang lain merepresentasikan pemakaian, Blischke dan Murthy (1994). Sedangkan kebijakan garansi tambahan adalah garansi yang ditawarkan setelah waktu garansi dasar habis.

Biaya garansi merupakan bagian dari biaya penjualan produk. Estimasi biaya garansi yang tinggi akan membuat harga jual dari suatu produk menjadi tidak kompetitif. Sebaliknya, jika estimasi biaya garansi lebih rendah akan mengurangi keuntungan perusahaan. Untuk melakukan perbaikan produk, produsen memiliki dua pilihan tindakan rektifikasi, yaitu perbaikan dan penggantian, Blischke dkk. (2011), Park dan Pham (2016).

Chukova, dan Johnston (2006) membagi wilayah garansi empat persegi panjang dan membaginya menjadi tiga subregulasi yang terpisah, sehingga masing-masing subregional ini memiliki tingkat perbaikan. Tujuan utama pembagian tersebut untuk menentukan subregional, sehingga biaya servis garansi yang diharapkan per item yang terjual diminimalkan. Selain itu terdapat penambahan parameter antara strategi yang sebelumnya, yang diharapkan parameter tambahan memperbaiki solusi optimal.

Kim dkk. (2001) serta Murthy dan Jack (2007) membahas biaya garansi satu dimensi dengan menggunakan satu variabel saja yaitu pemakaian atau umur produk. Studi yang dilakukan oleh Jack dkk. (2009) menganalisa model dua dimensi yaitu umur produk dan pemakaian produk. Hasil dari penelitian tersebut dapat digunakan untuk menentukan strategi perbaikan dalam masa garansi. 
Beberapa penelitian garansi dilakukan pada model dua dimensi dengan menitikberatkan pada pengaruh tindakan perawatan terhadap biaya garansi, antara lain penelitian Wang dkk. (2015). Wang dkk. (2015) mengembangkan strategi perawatan untuk produk. Pengelolaan perawatan yang optimal pada masa garansi dapat meminimalkan biaya garansi.

Studi topik garansi sudah banyak dilakukukan, namun masih terbuka peluang untuk diteliti dan diaplikasikan pada masalah praktis/riil. Pada penelitian ini dianalisa model biaya garansi pada produk otomotif dengan melihat faktor umur dan pemakaian. Garansi dilakukan pada bagian mesin. Biaya garansi tidak memasukkan biaya penggantian, karena komponen yang mahal. Sehingga biaya garansi dihitung berdasarkan biaya perbaikan dikalikan ekspetasi jumlah kerusakan. Perbedaan penelitian ini adalah ekspetasi jumlah kerusakan didapatkan melalui integral lipat dua dari fungsi hazard yaitu kerusakan komponen.

\section{Studi Literatur}

Blischke dan Murthy (1994) menyebutkan garansi merupakan kesepakatan kontraktual antara produsen dan konsumen berkaitan dengan penjualan produk. Dalam kesepakatan ini, produsen diharuskan melakukan perbaikan (rektifikasi) terhadap produk yang mengalami kegagalan dalam periode garansi. Garansi memberikan jaminan bahwa produsen akan melakukan perbaikan jika produk mengalami kegagalan fungsional di dalam masa garansi yang telah ditentukan.

Menurut dimensinya kebijakan garansi dikelompokkan kedalam dua kebijakan yaitu:

1. Kebijakan garansi satu dimensi

Kebijakan garansi satu dimensi dikarakteristikkan oleh satu atribut, yaitu umur produk atau pemakaian.

2. Kebijakan dua dimensi

Kebijakan garansi dua dimensi dikarakteristikan oleh dua atribut, dimana atribut pertama merepresentasikan waktu dan atribut kedua merepresentasikan pemakaian.

\subsection{Biaya Garansi}

Biaya garansi adalah biaya sulit ditetapkan. Tetapi biaya tersebut harus dikeluarkan produsen setiap unit penjualan bergaransi. Hal ini disebabkan produk bergaransi memiliki kegagalan produk bersifat acak. Kegagalan antara lain dapat dipengaruhi mutu produk dan cara pemakaian oleh masing-masing konsumen. Biaya garansi sangat penting bagi 
produsen karena biaya garansi merupakan bagian dari harga jual, oleh karena itu diperlukan estimasi yang akurat. Blischke dkk. (2011) merumuskan ekspetasi biaya garansi dengan:

$$
E(N)=C_{s} M(u, w)
$$

dimana,

$C_{s} \quad$ : rata-rata biaya untuk perbaikan

$E(N)$ : ekspetasi jumlah klaim

u : variabel untuk menyatakan umur produk

w $\quad$ variabel untuk menyatakan pemakaian produk

\subsection{Tipe Perbaikan}

Pada masa garansi produk dapat mengalami suatu kerusakan, tindakan dalam perbaikan merupakan faktor yang penting dalam pengelolaan garansi, Blischke dan Murthy (1994). Tipe perbaikan penggantian dibagi menjadi dua yaitu :

\section{Penggantian (Replacement)}

Kondisi produk pada kasus ini setelah diperbaiki diasumsikan sebaik kondisi seperti produk baru (pada saat pembelian). Dengan kata lain, distribusi waktu kegagalan produk yang telah diperbaiki akan sama dengan distribusi waktu kegagalan produk baru.

2. Perbaikan minimal (Minimal repair)

Pada kondisi ini setelah diperbaiki, maka produk dapat berfungsi kembali. Umur komponen penyusun produk sebelum mengalami kerusakan adalah sama, misal umur produk sebelum mengalami kerusakan adalah $x$, maka produk yang telah diperbaiki secara keseluruhan juga akan berumur $x$.

\subsection{Ekspektasi Jumlah Kerusakan}

Kerusakan garansi berpengaruh terhadap biaya garansi yang dikeluarkan oleh perusahaan. Ekspektasi jumlah kerusakan pada garansi dua dimensi didefinisikan oleh Pham (2006) dengan $M(u, w)$ yaitu kerusakan yang terjadi pada daerah yang dinyatakan dalam $[0, x) \times[0, y)$ sebagai:

$$
M(u, w)=\int_{0}^{w} \int_{0}^{u} h(x, y) d x d y
$$

dimana:

$h(x, y)$ : fungsi intensitas kerusakan (hazard) 


\subsection{Keandalan (Reliability)}

Keandalan adalah peluang suatu produk dapat beroperasi dengan baik pada periode waktu tertentu pada kondisi beroperasi tanpa adanya kerusakan, Bain dan Engelhardt (1991). Jika T adalah variabel acak yang menunjukkan waktu terjadi kerusakan suatu komponen tertentu maka peluang komponen berfungsi baik setelah waktu $t$ adalah:

$$
R(t)=P(\boldsymbol{T}>t)=1-F(t)
$$

\subsection{Fungsi Hazard}

Fungsi hazard dari suatu item dapat diinterpretasikan sebagai besarnya laju atau kecepatan suatu item mengalami kegagalan pada saat $t$. Fungsi hazard adalah probabilitas bersyarat bahwa suatu benda akan gagal pada interval $(t, t+\Delta t)$, Bain dan Engelhardt (1991) dirumuskan sebagai berikut:

$$
h(x)=\frac{f(x)}{1-F(x)}=\frac{f(x)}{R(x)}
$$

\section{Metodologi Penelitian}

Beberapa langkah-langkah berikut menjelaskan tahapan perumusan model biaya garansi.

\section{Langkah Pertama.}

Menentukan kegagalan komponen mesin, dengan asumsi kegagalan berdistribusi Weibull. Distribusi Weibull digunakan dalam pemodelan laju kerusakan yang tidak konstan atau bergantung waktu. Bain dan Engelhardt (1991) menyatakan, suatu variabel acak kontinu $X$ dikatakan berdistribusi Weibull dengan parameter skala yaitu $\theta>0$ dan parameter bentuk yaitu $\beta>0$, memiliki fungsi padat peluang sebagai berikut:

$$
f(x)=\left\{\begin{array}{l}
\frac{\beta}{\theta^{\beta}} x^{\beta-1} e^{-\left(\frac{x}{\theta}\right)^{\beta}} \\
0, x \text { yang lain }
\end{array}, \theta>0, \beta>0, x>0\right.
$$

Dengan fungsi padat peluang kumulatifnya yaitu:

$$
F(x)=1-e^{-\left(\frac{x}{\theta}\right)^{\beta}} \quad, x>0
$$

\section{Langkah Kedua.}

Perumusan kegagalan untuk garansi dua dimensi variabel yang berperan adalah variabel umur $(X)$ dan pemakaian $(Y)$. $X$ dan $Y$ merupakan peubah acak bebas statistik. Sehingga fungsi padat peluang dan fungsi padat peluang kumulatif dari distribusi Weibull adalah: 


$$
\begin{aligned}
& f(x, y)=f(x) f(y)=\left(\frac{\beta_{1}}{\theta_{1} \beta_{1}} x^{\beta_{1}-1} e^{-\left(\frac{x}{\theta_{1}}\right)^{\beta_{1}}}\right)\left(\frac{\beta_{2}}{\theta_{2} \beta_{2}} y^{\beta_{2}-1} e^{-\left(\frac{y}{\theta_{2}}\right)^{\beta_{2}}}\right) \\
& F(x, y)=F(x) F(y)=\left(1-e^{-\left(\frac{x}{\theta_{1}}\right)^{\beta_{1}}}\right)\left(1-e^{-\left(\frac{y}{\theta_{2}}\right)^{\beta_{2}}}\right)
\end{aligned}
$$

dengan $\theta_{1}>0, \theta_{2}>0, \beta_{1}>0, \beta_{2}>0, x>0, y>0$

\section{Langkah Ketiga.}

Menentukan kerusakan komponen mesin melalui fungsi keandalan komponen yang dinyatakan dengan:

$$
R(x)=1-F(x, y)
$$

Fungsi hazard atau laju kerusakan didefinisikan sebagai:

$$
h(x, y)=\frac{f(x, y)}{R(x, y)}
$$

\section{Langkah Keempat.}

Menghitung ekspetasi jumlah kerusakannya dengan

$$
\begin{array}{r}
M(u, w)=\int_{0}^{w} \int_{0}^{u} h(x, y) d x d y \\
=\int_{0}^{w} \int_{0}^{u} \frac{\frac{\beta_{1} \beta_{2}}{\theta_{1} \beta_{2} \beta_{2}} x^{\beta_{1}-1} y^{\beta_{2}-1}}{e^{\left(\frac{x}{\theta_{1}}\right)^{\beta_{1}}}+e^{\left(\frac{y}{\theta_{2}}\right)^{\beta_{2}}}-1} d x d y
\end{array}
$$

Didapatkan: $\quad M(u, w)=\left(\frac{u}{\theta_{1}}\right)^{\beta_{1}}\left(\ln \left|e^{\left(\frac{w}{\theta_{2}}\right)^{\beta_{2}}}-1\right|-\left(\frac{w}{\theta_{2}}\right)^{\beta_{2}}\right)-\operatorname{dilog}\left(\frac{1-e^{\left(\frac{w}{\theta_{2}}\right)^{\beta_{2}}}}{e^{\left(\frac{u}{\theta_{1}}\right)^{\beta_{1}}}}\right)$

$$
\begin{gathered}
-\ln \left|e^{\left(\frac{u}{\theta_{1}}\right)^{\beta_{1}}}+e^{\left(\frac{w}{\theta_{2}}\right)^{\beta_{2}}}-1\right| \ln \left|\frac{1-e^{\left(\frac{w}{\theta_{2}}\right)^{\beta_{2}}}}{e^{\left(\frac{u}{\theta_{1}}\right)^{\beta_{1}}}}\right|+\operatorname{dilog}\left(\frac{e^{\left(\frac{w}{\theta_{2}}\right)^{\beta_{2}}}}{1-e^{\left(\frac{u}{\theta_{1}}\right)^{\beta_{1}}}}\right) \\
+\ln \left|e^{\left(\frac{u}{\theta_{1}}\right)^{\beta_{1}}}+e^{\left(\frac{w}{\theta_{2}}\right)^{\beta_{2}}}-1\right| \ln \left|\frac{e^{\left(\frac{w}{\theta_{2}}\right)^{\beta_{2}}}}{1-e^{\left(\frac{u}{\theta_{1}}\right)^{\beta_{1}}}}\right|-\operatorname{dilog}\left(e^{\left(\frac{w}{\theta_{2}}\right)^{\beta_{2}}}\right) \\
-\frac{1}{2}\left(\left(\frac{w}{\theta_{2}}\right)^{\beta_{2}}\right)^{2}+\frac{1}{6} \pi^{2}-\operatorname{dilog}\left(\frac{1}{1-e^{\left(\frac{u}{\theta_{1}}\right)^{\beta_{1}}}}\right) \\
-\ln \left|e^{\left(\frac{u}{\theta_{1}}\right)^{\beta_{1}}}\right| \ln \mid \frac{1}{1-e^{\left(\frac{u}{\theta_{1}}\right)^{\beta_{1}}} \mid}
\end{gathered}
$$




\section{Langkah Kelima.}

Menetapkan ekspektasi biaya garansi menggunakan persamaan (1)

\section{Implementasi dan Pembahasan}

Pada bagian ini akan disimulasikan nilai ekspetasi biaya garansi yang ditanggung oleh PT. Indomobil Prima Niaga Sidoarjo dalam masa garansi 3 tahun atau pemakaian maksimal $100.000 \mathrm{~km}$. Data klaim produk selama pada tahun 2015-2016, dengan memilih produk Hino 300 series. Kerusakan item yang digaransi adalah bagian mesin, dengan subject kerusakan didominasi Countermeasure Brake Chamber. Menggunakan persamaan (5) fungsi padat peluang untuk distribusi Weibull yaitu sebagai berikut:

$$
f(x, y)=\frac{\beta_{1} \beta_{2}}{\theta_{1}^{\beta_{1}} \theta_{2}{ }^{\beta_{2}}} e^{-\left(\frac{x}{\theta_{1}}\right)^{\beta_{1}}-\left(\frac{y}{\theta_{2}}\right)^{\beta_{2}}} x^{\beta_{1}-1} y^{\beta_{2}-1}
$$

Untuk mengestimasi parameter digunakan metode Maximum Likelihood Estimation, dengan fungsi likelihood adalah:

$$
\begin{aligned}
& L(\hat{\theta})=\prod_{i=1}^{n} f_{i}(x, y), \text { dengan } \hat{\theta}=\theta_{1}, \theta_{2}, \beta_{1}, \beta_{2} \\
& =\prod_{i=1}^{n} \frac{\beta_{1} \beta_{2}}{\theta_{1}^{\beta_{1}} \theta_{2}{ }^{\beta_{2}}} e^{-\left(\frac{x_{i}}{\theta_{1}}\right)^{\beta_{1}}-\left(\frac{y_{i}}{\theta_{2}}\right)^{\beta_{2}}} x_{i}^{\beta_{1}-1} y_{i}^{\beta_{2}-1} \\
& =\left(\frac{\beta_{1} \beta_{2}}{\theta_{1}{ }^{\beta_{1}} \theta_{2} \beta_{2}}\right)^{n} e^{\sum_{i=1}^{n}\left(-\left(\frac{x_{i}}{\theta_{1}}\right)^{\beta_{1}}-\left(\frac{y_{i}}{\theta_{2}}\right)^{\beta_{2}}\right)} \prod_{i=1}^{n} x_{i}^{\beta_{1}-1} y_{i}^{\beta_{2}-1}
\end{aligned}
$$

Fungsi log-likelihood adalah:

$$
\begin{gathered}
\ln L(\hat{\theta})=n\left(\ln \beta_{1}+\ln \beta_{2}-\beta_{1} \ln \theta_{1}-\beta_{2} \ln \theta_{2}\right)+\left(\beta_{1}-1\right) \sum_{i=1}^{n} \ln x_{i}+ \\
\left(\beta_{2}-1\right) \sum_{i=1}^{n} \ln y_{i}-\sum_{i=1}^{n}\left(\frac{x_{i}}{\theta_{1}}\right)^{\beta_{1}}-\sum_{i=1}^{n}\left(\frac{y_{i}}{\theta_{2}}\right)^{\beta_{2}}
\end{gathered}
$$

Selanjutnya diturunkan terhadap parameter $\theta_{1}, \theta_{2}, \beta_{1}, \beta_{2}$, kemudian disamadengankan nol, seperti berikut:

$$
\begin{array}{r}
\frac{\partial L(\widehat{\theta})}{\partial \theta_{1}}=-\frac{n \beta_{1}}{\theta_{1}}+\frac{\beta_{1}}{\theta_{1}} \sum_{i=1}^{n}\left(\frac{x_{i}}{\theta_{1}}\right)^{\beta_{1}}=0 \\
\frac{\partial L(\widehat{\theta})}{\partial \theta_{2}}=-\frac{n \beta_{2}}{\theta_{2}}+\frac{\beta_{2}}{\theta_{2}} \sum_{i=1}^{n}\left(\frac{y_{i}}{\theta_{2}}\right)^{\beta_{2}}=0 \\
\frac{\partial L(\widehat{\theta})}{\partial \beta_{1}}=\frac{n}{\beta_{1}}-n \ln \theta_{1}+\sum_{i=1}^{n} \ln x_{i}-\sum_{i=1}^{n}\left[\left(\frac{x_{i}}{\theta_{1}}\right)^{\beta_{1}} \ln \left(\frac{x_{i}}{\theta_{1}}\right)\right]=0 \\
\frac{\partial L(\widehat{\theta})}{\partial \beta_{2}}=\frac{n}{\beta_{2}}-n \ln \theta_{2}+\sum_{i=1}^{n} \ln y_{i}-\sum_{i=1}^{n}\left[\left(\frac{y_{i}}{\theta_{2}}\right)^{\beta_{2}} \ln \left(\frac{y_{i}}{\theta_{2}}\right)\right]=0
\end{array}
$$


Proses selanjutnya digunakan metode Newton Raphson untuk mendapatkan nilai parameter $\theta_{1}, \theta_{2}, \beta_{1}, \beta_{2}$ pada persamaan (11)-(14), dan diselesaikan dengan Matlab.

Gambar 1 menyajikan deskripsi nilai ekspetasi jumlah kerusakan dengan periode waktu $(U)$ mulai 0 sampai dengan 3 tahun dan pemakaian $(W) 0$ sampai dengan $100.000 \mathrm{~km}$. Interval nilai $U$ disajikan antara 0 sampai 3 dengan penyajian selang waktu 1 tahun. Interval nilai $W$ disajikan dengan selang pemakaian tiap $25.000 \mathrm{~km}$.

Klaim garansi dinyatakan valid apabila klaim diajukan oleh konsumen masih dalam daerah garansi. Garansi dinyatakan habis apabila salah satu syarat terpenuhi. Nilai ekspetasi jumlah kerusakan dalam periode tahun pertama terdapat 4 sampai dengan 5 klaim, kemudian periode terakhir garansi antara 5-6 klaim. Hal ini menunjukkan dalam masa garansi tersebut, klaim yang diajukan oleh konsumen terhadap produk yang dibelinya mengalami kegagalan fungsional tahun ke-0 sampai ke-3 sebanyak 4 sampai 6 kerusakan. Selain itu terlihat bahwa ekspetasi jumlah kerusakan produk mengalami peningkatan sebanding dengan peningkatan jumlah pemakaian dan umur dari produk.

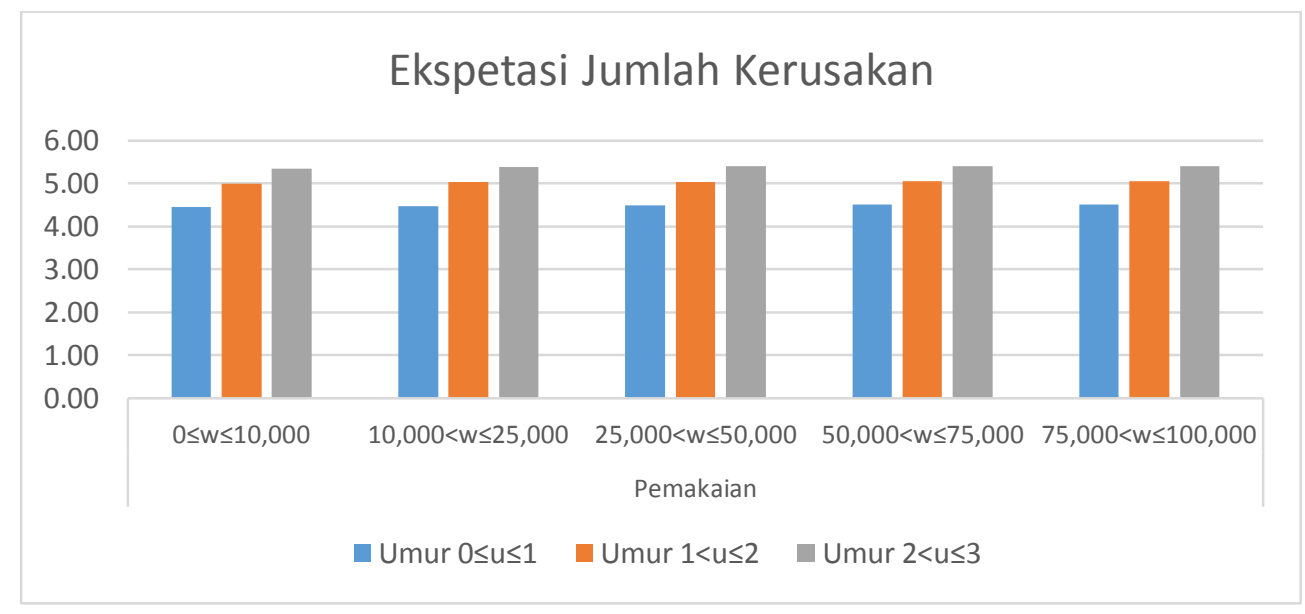

Gambar 1 Deskripsi dari Ekspektasi Jumlah Kerusakan 


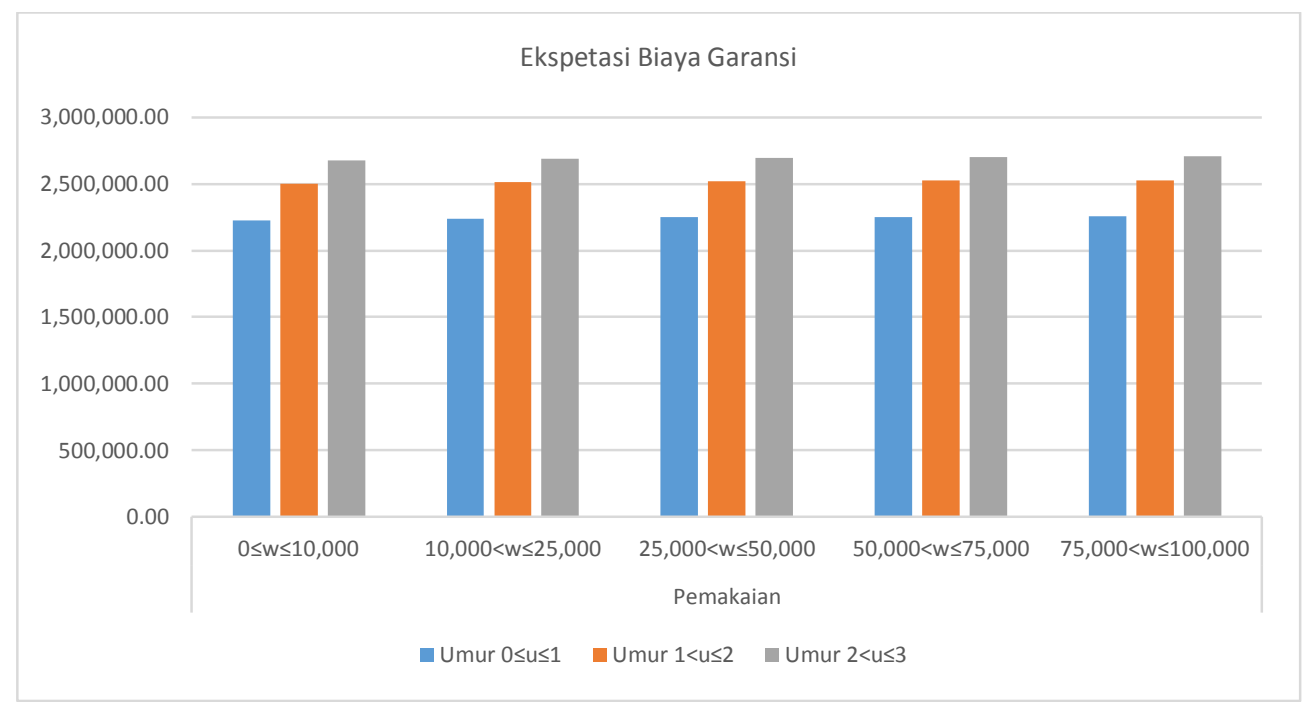

Gambar 2 Deskripsi dari Ekspektasi Biaya Garansi

Ekspektasi biaya garansi dinyatakan sebagai

$$
: E(P)=C_{s} M(u, w)
$$

Dengan $C_{s}$ menyatakan rata-rata biaya yang harus dikeluarkan produsen untuk meretrifikasi satu produk (per item) yang mengalami kegagalan.

Gambar 2 merupakan gambaran nilai ekspektasi biaya garansi merupakan perkalian antara nilai ekspektasi jumlah klaim dengan biaya perbaikan rata-rata produk. Nilai ekspektasi biaya garansi yan ditanggung masa garansi 0 sampai 3 tahun atau pemakaian maksimal $100.000 \mathrm{~km}$ sebesar sebesar Rp.2.000.000,- sampai Rp.3.000.000,-. Ekspektasi biaya garansi produk mengalami peningkatan sebanding dengan peningkatan jumlah pemakaian dan umur dari produk.

\section{Kesimpulan}

Penelitian ini menghasilkan model ekspetasi biaya garansi dua dimensi. Biaya garansi $E(P)$ dipengaruhi oleh rata-rata biaya perbaikan per item yang mengalami kegagalan $\left(C_{s}\right)$ dikalikan ekspetasi jumlah kerusakan $M(u, w)$. Ekspetasi jumlah kerusakan dirumuskan sebagai berikut:

$$
\begin{gathered}
M(u, w)=\left(\frac{u}{\theta_{1}}\right)^{\beta_{1}}\left(\ln \left|e^{\left(\frac{w}{\theta_{2}}\right)^{\beta_{2}}}-1\right|-\left(\frac{w}{\theta_{2}}\right)^{\beta_{2}}\right)-\operatorname{dilog}\left(\frac{1-e^{\left(\frac{w}{\theta_{2}}\right)^{\beta_{2}}}}{e^{\left(\frac{u}{\theta_{1}}\right)^{\beta_{1}}}}\right) \\
\left.-\ln \left|e^{\left(\frac{u}{\theta_{1}}\right)^{\beta_{1}}}+e^{\left(\frac{w}{\theta_{2}}\right)^{\beta_{2}}}-1\right| \ln \left|\frac{1-e^{\left(\frac{w}{\theta_{2}}\right)^{\beta_{2}}}}{e^{\left(\frac{u}{\theta_{1}}\right)^{\beta_{1}}} \mid+\operatorname{dilog}}\right| \frac{e^{\left(\frac{w}{\theta_{2}}\right)^{\beta_{2}}}}{1-e^{\left(\frac{u}{\theta_{1}}\right)^{\beta_{1}}}}\right)
\end{gathered}
$$




$$
\begin{aligned}
& +\ln \left|e^{\left(\frac{u}{\theta_{1}}\right)^{\beta_{1}}}+e^{\left(\frac{w}{\theta_{2}}\right)^{\beta_{2}}}-1\right| \ln \left|\frac{e^{\left(\frac{w}{\theta_{2}}\right)^{\beta_{2}}}}{1-e^{\left(\frac{u}{\theta_{1}}\right)^{\beta_{1}}}}\right|-\operatorname{dilog}\left(e^{\left(\frac{w}{\theta_{2}}\right)^{\beta_{2}}}\right) \\
& -\frac{1}{2}\left(\left(\frac{w}{\theta_{2}}\right)^{\beta_{2}}\right)^{2}+\frac{1}{6} \pi^{2}-\operatorname{dilog}\left(\frac{1}{1-e^{\left(\frac{u}{\theta_{1}}\right)^{\beta_{1}}}}\right) \\
& -\ln \left|e^{\left(\frac{u}{\theta_{1}}\right)^{\beta_{1}}}\right| \ln \left|\frac{1}{1-e^{\left(\frac{u}{\theta_{1}}\right)^{\beta_{1}}}}\right|
\end{aligned}
$$

Implikasi praktis dapat ditunjukkan dari hasil simulasi numerik pada pembahasan. Biaya garansi akan meningkat seiring dengan peningkatan jumlah pemakaian dan umur dari produk yang bersangkutan. Interval garansi yang diberikan mulai umur 0 sampai dengan 3 tahun dan pemakaian mulai 0 sampai dengan $100.000 \mathrm{~km}$. Batas perbaikan produk pada tahun ke 3 dan pemakaian $100.000 \mathrm{~km}$ memiliki nilai estimasi jumlah klaim sebesar 5 sampai dengan 6 kerusakan dengan ekspetasi biaya garansi sebesar Rp. 2.000.000,- sampai Rp.3.000.000,-

Penelitian ini dapat dilanjutkan dengan menambahkan jenis-jenis atau level kerusakan ke-n yang terjadi, khususnya pada umur dan pemakaian di tahun yang sama pada masa garansi.

\section{Pustaka}

[1] Bain, L.J., dan Engelhardt, M., Introduction to Probability and Mathematical Statistics, Second Edition, Duxbury Press, California, 1991.

[2] Blischke, W. R., dan Murthy D. N. P., Warranty Cost Analysis, Marcel Dekker Inc., New York, 1994.

[3] Blischke, W.R., Karim, M.R., dan Murthy, D.N.P., Warranty Data Collection and Analysis, Springer London Dordrecht Heidelberg, New York, 2011.

[4] Chukova, S., dan Johnston, M.R., "Two-dimensional warranty repair strategy based on minimal and complete repairs" Mathematical and Computer Modelling, 44,1133$1143,2006$.

[5] Jack, N., Iskandar B.P., dan Murthy, D.N.P., “A repair-replace strategy based on usage rate for items sold with a two-dimensional warranty" Reliability Engineering and System Safety, 94, 611-617, 2009. 
[6] Kim, C.S., Djamaludin, I., dan Murthy, D.N.P., "Warranty cost analysis with heterogeneous usage intensity" International Transactions in Operational Research, 8, 337-347, 2001.

[7] Menezes, M.A.J dan Quelch, J.A., "Leverage your warranty program" Sloan Managereal Review, 31, 4, 69-80, 1990.

[8] Pham, H., Springer Handbook of Engineering Statistics, Springer London Dordrecht Heidelberg, New York, 2006.

[9] Park, M., dan Pham, H., "Cost models for age replacement policies and block replacement policies under warranty” Applied Mathematical Modelling, 1-14, 2016.

[10] Wang, Y., Liu, Z., dan Liu, Y., "Optimal preventive maintenance strategy for repairable items under two-dimensional warranty" Reliability Engineering and System Safety, 142, 326-333, 2015. 